\title{
Discourse types in stand-up comedy performances: an example of Nigerian stand-up comedy
}

\author{
Ibukun Filani \\ $\mathrm{PhD}$ student, Department of English, University of Ibadan \\ phylani@yahoo.com
}

\begin{abstract}
The primary focus of this paper is to apply Discourse Type theory to stand-up comedy. To achieve this, the study postulates two contexts in stand-up joking stories: context of the joke and context in the joke. The context of the joke, which is inflexible, embodies the collective beliefs of stand-up comedians and their audience, while the context in the joke, which is dynamic, is manifested by joking stories and it is made up of the joke utterance, participants in the joke and activity/situation in the joke. In any routine, the context of the joke interacts with the context in the joke and vice versa. For analytical purpose, the study derives data from the routines of male and female Nigerian stand-up comedians. The analysis reveals that stand-up comedians perform discourse types, which are specific communicative acts in the context of the joke, such as greeting/salutation, reporting and informing, which bifurcates into selfpraising and self denigrating.
\end{abstract}

Keywords: discourse types; stand-up comedy; contexts; jokes.

\section{Introduction}

Humour and laughter have been described as cultural universal (Oring 2003). According to Schwarz (2010), humour represents a central aspect of everyday conversations and all humans participate in humorous speech and behaviour. This is why humour, together with its attendant effect- laughter, has been investigated in the field of linguistics and other disciplines such as philosophy, psychology, sociology and anthropology. Dynel (2009) opines that in its investigations in several fields like philosophy, psychology, sociology and anthropology, humour is taken as a single but multifarious phenomenon, however, the trend in linguistics analyses of humour is to narrow down the investigation to one of its specific manifestations, which are many. In this paper, stand-up comedy performance is examined from a linguistic perspective. 
The main purview of this study is to conceptualise different discourse types that can be found in stand-up performances. The study will serialise and categorise the routines of two Nigerian stand-up comedians into different discourse types. Conceptualising discourse types in stand-up comedy performance is made possible because of the nature of stand-up comedy speech situation. This speech situation is not peculiar to stand-up comedy performance only, it is also found in other joking situations.

Jokes, which are the focus of humour researches situated in linguistics, are best viewed as products of secondary speech situations. This is because, in joking exchanges, speakers report the speech or action of other individuals to hearers. Jodlowiec (1991: 244) describes secondary speech situations as "acts in which the speaker reports to the hearer on somebody's linguistic behaviour. By definition then, two sets of speakers and hearers are involved: on one hand, the joke teller and his audience and on the other, the characters in the joke." Bearing this view in mind, two speech situations can be identified in stand-up comedy routines: the first is the one between comedians and their audiences (context of the joke- we will term this as $\mathrm{C} 1$ ), and second is the speech situation found in the joking stories of the stand-up comedians (context in the joke- we will term this C2). Identifying speech situations in stand-up comedy is cardinal to conceptualising discourse types in any stand-up performance.

\section{Literature}

Stand-up comedy is a genre of popular culture which thrives on production and consumption of humorous utterances. It has been described as "an encounter between a single standing performer behaving comically and/or saying funny things directly to an audience" (Mintz, 1985: 71). There exist a couple of studies on stand-up performances, some of which are Adetunji (2013), Scarpetta \& Spagnolli (2009), Glick (2007), Yus (2004), Mesropova (2003) Rutter, (2000, 1997), Greenbaum (1999) and McIlvenny et al (1993). These studies highlight different aspects of stand-up performance from different disciplinary perspectives. However, in their analysis, none of these studies makes reference to stand-up comedy as a secondary speech situation and none of them attempt a discourse-oriented analysis of stand-up performance as a secondary speech situation.

Mintz (1985) is concerned with the social roles of the stand-up comedian as public joker who affirms or subverts culture. He describes a stand-up comedian as a "comic spokesperson," "a mediator, an articulator of culture and contemporary anthropologist" (Mintz, 1985: 75). Mesropova (2003) highlights the use of male denigrating motifs by Russian female stand-up comedians. Mesropova (2003) notes that Russian female stand-up routines discursively empower Russian women since their performances present Russian men as weak.

Rutter and Glick investigate the performance aspect of stand-up comedy. Rutter's goal is "looking at the way a joke is performed ...how it is received by the audience and how the dialogue between performer and members of the audience is ordered, maintained and regulated" (Rutter, 1997: 2). Glick (2007) looks into the textuality of temporalization as a performative technique in stand-up comedy performances. Specifically, Glick (2007) adopting Bakhtin's thesis on voicing in narrative chronotypes, explores verbal art in Eddie Izzard's performance. He focuses on how Izzard adopts voicing to create a dialogue between the coloniser and colonised. Greenbaum (1999) is a rhetorical analysis of stand-up performances. The author argues that stand-ups, by adopting Aristotlean and Isocratean notion of discourse (ethos, kairos, praxis and theoria), achieve rhetorical authority in their performances.

From linguistic perspectives, studies have taken different viewpoints and have investigated different aspects of stand-up comedy performance. Yus (2004) takes a relevance theoretic perspective to investigate the pragmatic strategies stand-up comedians employ in their 
routines and how such strategies entail the entertainment of background assumptions. McIlvenny et al (1993) is a conversational analysis approach to stand-up performance. McIlvenny et al (1993) explore how stand-up comedians create identities for their audiences through membership categorisation and how they strategically use "laughtraps" and other conversational devices like list, contrast pair and disclaimer to elicit laughter. Katayama (2008) presents a comparative study of Japanese Manzai and American stand-up comedy using participation framework and politeness theory. Katayama observes that in American stand-up performance, humour occurs with an in-group sphere created as the comedians decrease the distance between themselves and their audience; while in the Japanese context, the Manzai reinforces the distance between the performer and spectator, with laughter occurring based on the distinction between the performer's sphere and the audience sphere. Scarpetta \& Spagnolli (2009) is more concerned with how stand-up comedians create an informal interactional context for their performance in which they present jokes on sensitive topics such as sex and race. To Scarpetta \& Spagnolli, this interactional context enables the co-production of humour between the comedians and their audiences.

Adetunji (2013) is a study that is closely related to the present one in that it focuses on Nigerian stand-up comedy. Specifically, the study examines the interactional context of Nigerian stand-up comedy. Adetunji identifies the use of linguistic coding (which involves code selection, code alternation and pausing), stereotyping, formulaic expressions, call-andresponse, self-deprecation and shared experiences as pragmatic strategies employed by Nigerian comedians to co-produce humour with their audience. Other closely related studies to the present one are Waisanen (2011) and (2014) which explore the act of politicization in the discourse of stand-up comedians. Waisanen (2011) and (2014) highlight the rhetorical significance of stand-up discourse, noting that stand-up comedians project interpretive acts which include different rhetorics like optimism, uncertainty, realism and egocentrism. Waisanen sees stand-up comedy as a pervasive mode of public communication.

As suggested earlier, the previous studies on stand-up comedy performances do not underscore the two speech situations in stand-up performances. At best, they only identify one speech situation, C1, which I will also conceptualise as context of the joke. In these studies, this speech situation is conceptualised as interactional context of stand-up comedy (Adetunji 2013; Scarpetta \& Spagnolli 2009). According to Adetunji (2013), the interactional context is based on the co-presence and co-operation of comedian and audience. According to him, it is made up of "the local linguistic and extra-linguistic forms and background knowledge, relevant to the production and consumption of humour, and oriented to by both comedian and audience" (Adetunji, 2013: 2). For the present purpose, the $\mathrm{C} 1$ is conceptualised as broader than Adetunji's interactional context. In addition to features identified by Adetunji (2013), C1 highlights a common knowledge or shared beliefs by both comedians and audiences. Thus, it contains participants shared language(s) knowledge, shared knowledge of stand-up practice, and shared encyclopaedic and cultural knowledge.

It is important to state that some studies have also attempted serialising the sequential organisation of stand-up performance into bits. Rutter $(1997 ; 2000)$ cited in Scarpetta \& Spagnolli (2009: 6) identify the following successive bits in British stand-up comedy:

i. Introduction, in which the compere announces the comedian, evaluates him/her, and warms up the audience, whose responses to the compere accompany the entrance of the comedian on stage;

ii. The comedian entrance, which overlaps with the audience applause. S/he starts with an opening in which s/he greets, comments, and trains the audience in the way to respond. These exchanges are used to orient the audience towards the nature of the routine and also to divert the audience attention from drinks and chats

iii. The body of the show, which is made up of several joke-telling sequences 
iv. The closure, which is made up of a series of not necessarily funny utterances like the evaluation of the audience, a reintroduction of the comedian, and thanks that accompany her/his departure from the stage.

Similarly, focusing on the interactive context of the performance, Scarpetta \& Spagnolli (2009) serialise stand-up performances into the following:

i. Starting the interaction: this is the beginning of each stand-up comedy performance. It is "a time where the comedian and the audience can start working together at defining the interactional context in which all subsequent jokes will be located" (Scarpetta \& Spagnolli, 2009: 9).

ii. Transition to a new joke sequence: this phase highlights the institutional reason for the stand-up encounter and it also refers to the methods adopted by the comedian to "organise the movement from one joke sequence to the next" (Scarpetta \& Spagnolli, 2009: 9). According to them, comedians may adopt fillers and surveys in order to achieve this transition. Fillers complete a previous joke sequence while surveys prepare the punch line for the next sequence.

iii. Expanding successful jokes: the act of expanding successful jokes is carried out by presenting a cascade of punch lines that rely on the premise of the first one. Such series of punch lines are called pags. Apart from pags, comedians can also use accounts in expanding the success of a joke sequence. According to Scarpetta \& Spagnolli (2009: 16), "accounts expand the joke sequence to take care of aspects that might be questionable in the joke, even in the presence of expression of an affiliation from the audience".

iv. Referring to the audience in the punch line: by this, Scarpetta \& Spagnolli (2009) mean instances where the stand-up comedians exploit the audience (audiencereferred humour) as well as themselves (self-referred humour) as material for humour. Such a practice "contributes to making the register of the encounter personal" (Scarpetta \& Spagnolli, 2009:17).

Both Rutter's and Scarpetta and Spagnolli's groupings of the performance is carried out within the purview of the context of the joke which is the speech situation consisting of stand-up comedians and audiences. The current study is predicated upon the thesis that a linguistic analysis of stand-up comedy performance must not only consider the $\mathrm{C} 1$, but it must also examine the $\mathrm{C} 2$. In other words, a linguistic analysis should reflect that stand-up performance is a product of secondary speech situation. If this view is taken, the goal of the analysis will not just be the event between comedians and audiences, but it will also take cognisance of the events in the joking stories, which are reflective of language culture and other shared beliefs or knowledge of the participants.

\section{Context in the joke}

By differentiating context in the joke $(\mathrm{C} 2)$ from the context of the joke $(\mathrm{C} 1)$ in stand-up performance, I presuppose a dynamic nature of and a double-layered context. The $\mathrm{C} 2$ keeps changing as much as stand-up comedians present their audiences with different and multiple joking sequences in a routine. Furthermore, the $\mathrm{C} 2$ is embedded in the $\mathrm{C} 1$ which remains fixed as long as the interaction between a comedian and her/his audiences continues.

The previous studies (e.g. McIlvenny et al. 1993); Scarpetta \& Spagnolli 2009; Adetunji 2013) explain $\mathrm{C} 1$ focusing on the situation in which both comedians and audiences realise their aims. Their explanatory movement is from the outside in, since in analysing linguistic aspects of stand-up performance, these studies invoke the situation in which stand-up comedians and their audiences find their ways to explain what is being done in the interaction. This stance 
overemphasizes the fixed context. It leaves out the fact that in a routine, there are several joking stories with different targets, situations and other participants. Their stance also ignores the fact that these aspects of a joke play an important role in interpreting a performance. For instance, the choice of a target will determine the kind of background beliefs (most especially stereotypes) the audience will activate in interpreting the joke. What happens in any performance is that $\mathrm{C} 2$ interplays with $\mathrm{C} 1$ : in $\mathrm{C} 1$, stand-ups present $\mathrm{C} 2$ in a way that the audience will find $\mathrm{C} 2$ humorous. The interplay of $\mathrm{C} 1$ and $\mathrm{C} 2$ is therefore based on the standups' "creative distortion" (Mintz, 1985: 79). For both comedians and audiences, there is a movement in both directions, from the fixed $\mathrm{C} 1$ to the dynamic $\mathrm{C} 2$ and vice versa.

Since C1 has been delineated (see Adetunji, 2013: 2; Scarpetta \& Spagnolli 2009), I will focus on highlighting the features of $\mathrm{C} 2$. I propose that $\mathrm{C} 2$ is made-up of the joke utterance, participants/characters in the joke, and the activity/situation in the joke. These features are also contextualisation cues that are cardinal to the development and interpretation of a joke sequence. They determine audiences' inferences and the act of their getting the joke as they are pointers to the background knowledge or beliefs that are needed for the interpretations of the comedian's monologues.

The joke utterance refers to the exact linguistic code used by stand-ups to convey jokes to their audience. It presupposes language in joking exchanges, which according to Attardo (1994), contains all information necessary for the verbalisation of a joke. It includes phonological, lexical and structural choices of stand-up comedians as well as the semantic and pragmatic meanings of their choices. In a multilingual setting like Nigeria, the choice of linguistic code in stand-up performance is strategic. Specifically, Nigerian stand-ups use Nigerian Pidgin (NP) as an affiliative resource to speak with, and not to, their audiences (Adetunji 2013). Also NP serves as a tool for reaching a larger audience across ethnolinguistic and other social boundaries. NP is widely spoken in the country and unlike English ${ }^{\mathrm{i}}$, which is spoken by educated Nigerians, NP is spoken by both uneducated and educated citizens. Therefore, unlike English which would have limited the number of audiences because of the language barrier, NP gives Nigerian stand-up comedians the opportunity of attracting more people. Apart from this, a comedian may strategically choose a language variety, code mix/switch to activate background knowledge. For instance, a stand-up comedian who started his narration in NP may switch to a native language or regional variety of Nigerian English to activate stereotypical beliefs in the audience.

The participants in the joke are characters/people in the joking stories of stand-up comedians. Whenever stand-up comedians present their monologues, they assign utterances, actions, behaviours and attitudes to characters in their jokes. These characters may be real or imaginative. When they are used, real characters are representative of individuals or social groups in the wider society. Stand-up comedians do use referring expressions (real or pseudo names) to denote or connote such individuals or social groups. The audience picks out the referring expressions and then assign the proper referents to them. This is where shared cultural knowledge and language come into play in stand-up performances. If the audience do not have the same or similar experience with the stand-ups, they will not be able to interpret the characters in the joking stories. In addition, both the stand-ups and audience need to draw from their background knowledge of culture and language to be able create characters and assign roles to them in the joke, and, identify such characters and interpret their roles. How characters in the joke are presented, the actions and statements assigned to them, and the attendant audience acceptance of such presentations are pointers to an aspect of $\mathrm{C} 1$ - stand ups and audience attitudes to them and ultimately the discourse type performed by the stand-up. A stand-up comedian may choose to present a character in the joke as wise and smart or foolish and stupid, such representation of the character will be used to justify the stand-up comedian's act of criticising or praising the character. 
The activity in the joke has to do with events, actions or doings found in stand-up comedians' joking stories. Technically, it is what the stand-up joking story is all about. Standups joking stories are based on everyday activities (Schwarz 2010). The activity in the joke could be crossing the road, visiting a zoo, writing an examination, voting, talking with parent/children or any event/action comedians know that the audience can easily recognise as part of their daily living. Stand-ups' manner of presentation of an activity in their joking stories is directly linked to realising their interactional goal since their manner of presentation is an invitation to view the world in an alternate way. As joking stories are presented, audiences are able to connect with their cultural knowledge and see if the way it is presented is in consonance with what holds in their customs. There may be some sort of incongruity between the event or action reported in the joke and how the event or action should have been actually carried out.

\section{Discourse types (DT)}

Because discourse types are in a complimentary relationship to activity types (AT) (Odebunmi 2010; McIntyre \& Culpeper 2010), it is important to begin this section by examining what activity type is. According to Levinson (1979), an activity type is a group of speech acts and other conversational contributions which stand in particular pragmatic relationships to each other such that, as a whole, they make up a conventionalised activity. With the concept of activity type, Levinson focuses on the participants' verbal contributions which are constrained by the activity they perform and the situation of their interaction. The constraints on verbal contributions of participants are derived from the situational factors that surround the activity. Participants negotiate the constraints to make their contributions. Thus, in an activity type, we can say that there is a connectedness among the activity, its situational factors and the verbal contributions in the activity, such that the verbal contributions of the participants mirror the activity type and situational factors.

Because of the wide range nature of activity types, Sarangi (2000) introduces DT to characterise forms of talks within an activity type and to refer to different linguistic acts that are performed in an activity type. With DT, the inherent problem of setting definition boundaries within an activity type while conducting an analysis is solved. A DT is a goal driven contribution or series of exchanges in an interaction, hence, Sarangi (2000: 1) describes it as "specific manifestations of language form in their interactional contexts". DTs are used strategically with peculiar stylistic, sequential and structural properties. A DT is a genre of speech function or utterance force found in an activity type. To Odebunmi (2010), DTs are specific acts, relative to ATs and are institutionally-based.

It is important to state that AT and DT have a lot in common with the concept of acts in pragmatics, specifically, pragmatic acts developed by Mey (2001). Pragmatic act theory (PAT) is a further specification of J.L. Austin's and John Searle's theories of speech acts. In speech acts and pragmatic acts theories, the goal is to identify communicative significance of utterances. Major criticisms on speech act theory have been premised on the notion that the theory concentrates on speech to the exclusion of other phenomena like gestures, intonation, facial mimics, body posture, head movement and laughter, and that speech acts are not situated in contexts where they are used (Mey, 2001; 2006). In PAT, these extralinguistic features are included. In PAT, Mey (2001) identifies a common scene which is synonymous with AT in that a common scene accentuates the constraints as well as affordances imposed on language users by the speech situation. Acting in PAT, which is conceptualised as pragmeme, is a pragmatic view of speech acting and a means by which participants adapts context to themselves and adapts themselves to context. An instantiated pragmeme is a pract, which is an 
individual pragmatic act. A pract, like DT, refers to a situated action in a speech event. In addition, a DT, like a pract, highlights communicative significance of an utterance.

It is important to state why we find AT and DT relevant to the analysis of stand-up discourse. ATs and DTs characterise language behaviours drawn from institutional and/or professional domains. Stand-up comedy performance generates a form of institutional talk originating from professionals- the stand-up comedians themselves.

\section{Stand-up comedy as an activity type (AT)}

One of the major objectives of Levinson (1979) is to show how the structural properties of an activity constrain the verbal contributions that can be made towards the success of the activity. To argue that a Stand-Up comedy interaction is an activity type, there is need to follow the features identified by Levinson as defining an activity type: the structure of the activity, the kinds of constraints that defines the structure of the activity and the inferential schemata adopted in such activity.

To begin with, the structure of stand-up performance enhances the comedians' contributions and impedes audience contributions. Structural roles assigned to comedians and audiences differ and are out of balance. Stand-up comedians are permitted to dictate the pattern of talk, kinds of jokes and even points at which the audience could give their responses. To foreground the institutionalised role of comedians, they have their voices amplified and they perform where they can be easily sighted by everyone in the audience. Both the participants, the comedians and the audiences, recognise their roles. Comedians begin by working the room (Mintz 1985), after which they present a succession of joking stories. The audience are well aware that their role is to observe comedians' theatricals, and watch for contextualisation cues that will prompt their responses. Technically, we say the audience do not hold any turn for speaking. They only get entertained by comics' theatricals. However, stand-up comedians' goal is to attract and sustain the interest of the audience throughout the performance (Schwarz 2010).

Secondly, stand-up performance influences inferential patterns adopted by both comedians and audiences. In other words, stand-up activity determines how stand-up comedians will construct and present their theatricals as well as how the audience will interpret stand-ups' joking stories. Stand-up performances require that there should be a collective knowledge among the participants about the contents and structure of the performance and how it is supposed to proceed (Rutter 1997; Yus 2004). I have described this above as shared beliefs (see 3 above). Part of the shared beliefs is that the non-bona-fide mode of communication is activated. Following Raskin (1985), Attardo (1994) notes that the most important consequence of non-bona-fide mode is that speakers are not committed to the truth of what they say, unlike in bona-fide mode where they are committed to the truth of their propositions. Nonetheless, speakers do use jokes to convey relevant bona-fide information. Stand-up comedians are aware that their jokes could carry certain social imports, therefore, they overtly deny that their jokes have extra- performance significance. In Nigerian stand-up comedy, stand-ups do frame their joking stories with a pragmatic marker- na joke I dey $o$ [it is only a joke] which may come at the start or end of a joke. This pragmatic marker warns the audience that they cannot hold the stand-up comedians accountable for the bona-fide information they gather from the performance.

In addition, stand-ups' ability to predict the audience psychological state and the kind of joking stories that will cut across the audience (Yus 2004) are intangible aspects of the performance which also influence the inferential patterns of the participants. Because of the shared beliefs, stand-up comedians could predict issues that could easily attract audience attention and would be easily accessible to the audience. On their part, according to Yus (2004), 
the audience are in the mood to be entertained. Therefore, the audience are geared towards finding what is humorous in the joking stories.

The inferencing in stand-up performance is guided by the search of relevance (Yus 2003 ; 2004). Stand-up comedians are able to provide humorous stimuli and the audience are able to interpret them because both the comedian and audience adhere to the principle of relevance. It could be argued that they are guided by Grice's (1975) conversational maxims but the nature of the performance does not permit this because the talk is one sided. Besides, it is an interaction where one of the participants (the comedians) is permitted not to cooperate a la Grice. Raskin (1985) has linked humorous utterances with the overt application of the cooperative principles $(\mathrm{CP})$, noting that the $\mathrm{CP}$ states the prerequisites for bona-fide communication while humorous exchanges are instances of non-bona-fide communication. In humorous exchanges, the participants cooperate not to adhere to the cooperative principles. Yus (2003: 1298) argues that "humourists may be willing to keep relevant information to themselves, be obscure, be ambiguous... for the sake of pursuing the creation of humorous effects, but the principle of relevance invariable applies to both humorous and non-humorous discourse, without having to evoke any principle of cooperation or maxims whose flouting justifies these effects".

\section{Methodology}

The data for this study was drawn from Nigerian stand-up comedy. Specifically, I focused on the performances of two comedians who are making distinct marks in Nigerian stand-up comedy. These comedians, Youngest landlord and Helen Paul, were chosen because of the unique style with which they construct their joking stories. Unlike the other comedians, the selected comedians usually adopt relatively short build-up for their joking monologues. Thus their jokes are characterised with brevity and swift fabrication of incongruity. They therefore do not unnecessarily keep their audiences waiting too long for the punchline. In the selected routines for this study, the audience reactions revealed that their joking stories were highly appreciated, as they were accompanied with deep and extensive laughter.

Nigerian stand-up comedy is made available in video-compact-disc formats (VCD). Youngest landlord and Helen Paul routines were transcribed from VCD and presented in the analysis as illustrations. Youngest landlord's performance was taken from Nite of a thousand laughs (NTL), the oldest brand of Nigerian stand-up comedy, while Helen Paul's performance was taken from thecomedyberlusconi which is produced by Gordons, a popular Nigerian standup comedian. NTL is produced and directed by Opa Williams and it has been on since 1996. It is staged in different locations in Nigeria, especially in major cities like Lagos, Abuja, PortHarcourt, Enugu and Benin on national holidays. It features the progenitor of the Nigerian stand-up comedy, Ali Baba, and other popular stand-up comedians like AY, Basketmouth, I Go Dye, Gordons and Seyi law (for an overview of Nigerian stand-up comedy, see Adetunji 2013 and Ayakoroma 2013).

Nigerian stand-up comedians perform primarily in Nigerian Pidgin (NP), which could be alternated with either English or one of the numerous first languages in country; therefore, English translations of the comedians' monologues were presented in the paper. For ease of analysis, I focused initially on Youngest landlord's routine while latter on, while analysing discourse types, I drew from both Helen Paul's and Youngest landlord's routines. 


\section{Analysis and Findings}

To begin with, this monologue is extracted from an activity type, (Nigerian) stand-up comedy performance. Following Adetunji (2013), the following observations are made on the performances of Youngest landlord.

\section{The choice of linguistic code}

In speech exchanges, there are determining factors that influence the choice of language for the interaction. Specifically, such choice will be influenced by the linguistic repertoire of the participants, the AT in which they are engaged in and their intentions for making their utterances. Linguistic code choice in Nigerian stand-up comedy is a reflection of the country's multilingual situation. Nigerian stand-up comedians are multi-lingual in at least one of the several native languages in the country, English and Nigerian Pidgin (NP). Commonly, linguistic code choice in Nigerian stand-up performances is made from one these languages. One would think that the comedians will favour a language that conforms to Ferguson's high status; however, due to their desire to reach a wide audience, Nigerian stand-up comedians favour NP as the language of their performance. Because of the use of NP by comedians, NP has been associated with comedy in the country. NP, therefore, highlights and foregrounds the comedians' intention to initiate laughter in the audiences. The comedians use it to frame the audience's interpretation into non-bona-fide mode.

Part of linguistic coding is the comedians' deliberate adoption of code alternation (code switching and code mixing) during their performances. Specifically, it has been observed that comedians do code switch in order to orient their audiences (Adetunji 2013; Furukawa, 2007)

Youngest landlord's routine presents a peculiar and strategic use of linguistic coding. As shown in Extract 1, the comic begins his performance with a marked language choiceEnglish, rather than the unmarked language choice- NP. According to Myers-Scotton (1993), this kind of linguistic choice is motivated by the marked choice maxim in which speakers negotiate language choice to create social distance or aesthetic effect. Marked language choice by Youngest landlord is to create an aesthetic effect in his performance. The strategic use of English here is to carve a niche for himself in the comedy business which has been dominated by other popular stand-ups who normally begin their performance in NP. The use of English thus frames the audience to expect a performance in a language that is not commonly used for comedy voice.

\section{Extract 1.}

Good evening ladies and gentlemen. You are welcome. My name is youngest landlord, comedian of the Federal Republic of Nigeria.

I've realised in comedy,

It is not all about cracking jokes with Pidgin English

That actually makes you a professional comedian, you understand?

Having keyed the audience to have an unexpected assumption about his performance through his use of English, Youngest landlord switches his code from the marked code (English) to the unmarked code (NP) (see Extract 2 below). Technically, it would be said that he uses English to lead the audience in a garden path in which they are made to believe that the comedian would perform in English, however, when he switches to NP, the comedian presents a punchline which invalidates the belief instantiated by his use of English. Apart from the choice of 
linguistic code, the overt interpretation of the comedian's utterances in extracts 1 and 2 also validates this analysis.

Extract 2.

As a comedian you gat! to use! English! in cracking your jokes

That will make the audience know you are a little bit educated

You understand?

Most audience think that we comedians, we are drop out ${ }^{i i}$, you understand,

That's why I will be the first comedian! tonight!!

that will be cracking my jokes with simple! and correct! English! (P) (AC)

I think I deserve another round of applause (AC)

He get one man en (AL) [Translation: there is one man $]^{1}$

The switch to NP in the last line of Extract 2 is also strategic as it has performance significance. Here, using NP indicates that he has completed the act and art of starting the interaction and he is about to transit to his first joke sequence. Thus, his linguistic code choice is to reframe the audience to the non-bona-fide mode of interaction. It is important to comment on the comedian use of gat in the first line of Extract 2. Gat here translates to English verb - have. The use of gat in an English matrix sentence is an instance of code mixing. The use of gat is deliberate, it is not due to Youngest landlord's incompetence in English or psychological factors (see Gumperz 1982); Kim (2006) for reasons why bilinguals adopt code mixing and code switching), but rather, it is situational and intentional. Gat is Nigerian English slang. The comedian uses it for emphatic purpose. Also, it creates a stylish image for the comedian, such that the audience will view him as "trendy" in his use of language.

Another instance of code switching, which is illustrated in Extract 3 below, is also found in Youngest landlord's routine.

\section{Extract 3.}

Benin people wei dey here oba ato kpeye $e^{\mathrm{iii}}$ [Translation: Benin people in the audience (Benin cultural salutation)]

In 3, Youngest landlord switched from NP to Benin dialect. Here again, the switch is strategic and significant for his performance. Switching to a local language is suggestive of the targets of his joke. By directing his utterance to the Benin people in the audience, he deliberately creates a phenomenon of segregated audience, such that the audience would realise that there are two categories among them: members of the audience who are not Benin and members of the audience who are Benin. In Mcllvenny et al (1993) term, this is an instance of invoking membership category that is inference-rich for the audience. Youngest landlord's reference to Benin people and his subsequent use of a Benin dialect phatic utterance is to invite the audience to identify, affiliate or disaffiliate with Benin people and culture. He will then build humour on the knowledge available for Benin membership category, which has just been evoked, by making unfavourable references to Benin people. In this instance, the switch to Benin dialect indicates that the butt of his subsequent joking story is Benin people. His membership categorisation is to set up relevant background knowledge about the Benin people in the audience, which will be used to interpret his joke sequence.

\footnotetext{
${ }^{1}$ See Appendix for transcription conventions.
} 


\section{Stereotyping}

Stereotypes are fixed notions that people have about someone, something or a concept. Neria (2012) suggests that they are social imageries which could be exaggerated and absurd. In humour analyses, stereotypes have been found to be a nimble tool for humourists. Gruner (1997: 99) observes that "a stereotype is merely a very handy kind of shorthand to provide the essential framework for understanding the content of a joke". Similarly, Attardo (1994) notes that one of the ways by which jokes convey bona-fide information is by presupposing knowledge of stereotypical scripts which forms a part of script of the users of the humour. Stand-up comedy performances are avenues where stereotypes are perpetuated.

Stereotyping is made possible by setting up relevant background knowledge. Stand-up comedians have to draw from their cultural beliefs which they may share with the audience in order to humorously stereotype the target in their jokes. In Extract 1 and 2, Youngest landlord stereotypes, explicitly, Nigerian stand-up comedians as uneducated and drop-outs because of their consistent use of NP, and implicitly, as Nigerians who cannot speak correct English. He also stereotypes Benin people as drug and alcohol addicts (Extract 4).

\section{Extract 4.}

Na only Benin you go see chemist wei dem dey sell Igbo And na beer dem dey take drink the medicine

Benin no dey carry last! [Translation: It is only in Benin you will find a chemist selling marijuana as medicine. It is beer that they use for taking the medicine. Benin people are never beaten at their trade]

Youngest landlord presents an absurd proposition in stereotyping Benin people as drug and beer addicts. A chemist's is a place where approved and legal drugs are sold, but in the extract, he asserts that chemists in Benin commonly sell to people the contraband substance, marijuana. He also explicitly expresses Benin's people love for beer by noting that they also use the alcoholic beverage for taking the illegal substance. In these instances of stereotyping, Youngest landlord foregrounds and exaggerates characteristics of Benin people- their use of marijuana and love for alcohol. Through foregrounding and exaggeration, the absurdity of selling marijuana by chemists and consuming it with beer, just like medication, an incongruity is evoked in the audience watching the performance.

\section{Self-denigrating humour}

According to Dynel (2009), self-denigrating humour is a pragmatic type of humour which occurs when a speaker directs brickbats at him/herself. It is also known as self-disparaging or self-deprecating humour and self-mockery or self-directed joking. In stand-up performances, self-denigrating humour is significant in that it is usually employed for premeditated selfpresentation politics in the performance of jokes. Thus, self- denigrating jokes should be viewed as a contextualisation cue (in the sense of Gumperz 1992) in the performative context of jokes and art of using humour. In view of this, Adetunji (2013) treats self-denigrating jokes as de-emphasizing the institutional and conversational authority of the stand-up comedians. It should be added that it is a manifestation of the comedian's performative technique, stagecomposure and stage-intelligence, as Dynel (2009) observes that a self-denigrating joke displays its users' positive self-image and a contemporary social virtue- the ability to laugh at one's inabilities. 
As shown in Extracts 5 and 6 below, Youngest landlord richly deploys self-denigrating jokes in his routine, as he perspectivised his family background as abjectly poor and his way of dressing as appalling.

\section{Extract 5.}

My bros, I Go Dye, wei package me

I beg make you clap for I Go Dye (AC) and Opa Williams and Ali Baba ${ }^{\mathrm{iv}}$ in the building

Clap for them (AC)

Na them package me like dis come make me dress like mortuary attendant $(\mathrm{P})(\mathrm{AL})$

Oh my God! [Translation: My boss, I Go Dye, costumed me, please clap for him, and Opa Williams and Ali Baba in the building, clap for them. They are the one who dressed me for this performance and made me dressed up like a mortuary attendant]

\section{Extract 6.}

My father was not poor before I started comedy.

My papa no poor only say na only him wan get 12 chargers, him no get handset (AL)

Na only my papa buy moto the way dem dey build house

He first buy 4 tyres, we no know say na moto he dey buy (AL)

Before we know he buy boot, we no know (AL)

As we dey look the next two years nah in he buy engine

Only him come construct the motor,

motor come become the combination of different different spare parts

Benz windscreen, trailer tyre (AL) engine na watin them they take grind garriv (AL)

[Translation: my father was not poor only that he had 12 phone chargers without having a phone. It was only my father that bought a car the way a house is built. He started by buying 4 tyres, we never knew he was constructing a car. In no time, he bought the boot, we had no idea of what he was up to. In next two years, he bought the engine and before we knew it, he had constructed the car all by himself. The car was a combination of different spare parts from different brands of car. Mercedes Benz windscreen, trailer tyre, while the engine is Garri milling machine]

In Extract 5, Youngest landlord mockingly referred to his style of dressing. The comedian was dressed formally in a black tie, red shirt, black jacket, trousers and suit. Thus, the comedian seems highly presentable, attractive and amiable, and for the audience, the comedian's attire presents him as tidy and neat. It is also worthy to mention that in his attire, Youngest landlord fits into Ayakoroma's (2013) portrayal of Nigerian stand-up comedian wearing designers' suits as professionals. However, Youngest landlord chooses to make fun out of his seemingly welldressed pattern.

To initiate his denigrating motif, Youngest landlord adopts sarcasm, which initially suggests that he would praise his style of dressing, but which reveals that he distastes his fashion-style for the performance. His sarcastic remarks about his dressing overtly contradicts what the audience can perceive, thus, it presents an unexpected and surprising "foregrounding" (Glick, 2007: 292). The foregrounding here is Youngest landlord's direct linking and comparison of his tidied dressing with that of a mortuary attendant. He thus indirectly suggests that dressing well does not fit the act of stand-up performance. The mockery of his dressing depicts him as a professional comedian who makes humour out of any and every thing. The denigrating humour here is one that portrays the comedian as improperly dressed.

Likewise, in Extract 6, using the tools of sarcasm and exaggeration, he casts aspersions on his father. He begins by overtly asserting that his father was not in any way poor, unlike the other comedians who make humour from ridiculing the socio-economic status of their parents. Thus, he leads the audience in a garden path to assume that his father's economic status is 
buoyant. To strengthen the garden path assumption, he asserts to the audience that his father has 12 phone chargers before delivering the punch line that his father has no phone, which is incongruous with the propositions he has expressed about his father. He further strengthens the self-denigrating motif of his parentage by narrating how his father singlehandedly constructed his car by himself, as an index of his poor socio-economic status.

To further appreciate the effects of this disparaging joke about the socio-economic status of his parentage, one needs to consider a common cultural belief in Nigeria. In several cultures in the country, it is aberrant for someone to cast aspersions on his/her parentage. Slandering one's parentage is seen as disrespectful and contemptible. Thus, culturally, it is incongruous to disparage one's father. The act of disparaging his father in the context of standup performance places the audience in a shock. Having thus openly challenged a collectively held belief, he further expands the depth of the humour and mockery of his parents.

\section{Discourse types in stand-up performances}

As argued in Section 2, this study is predicated on the need to recognise both C1 and C2 in a stand-up routine while analysing the jokes in stand-up performances. Nevertheless, in analysis, $\mathrm{C} 2$ should be situated in $\mathrm{C} 1$, since $\mathrm{C} 2$ is embedded in and produced by $\mathrm{C} 1$. In this section, I situate the context in the joke in the activity type of Nigerian stand up performance to identify the discourse types that is articulated by stand-up comedians.

\section{Salutation/greeting DT (SDT)}

Salutation DTs function as preludes in the performances of stand-up comedians. In Nigerian stand-up comedy, SDTs are important as typical performances in the country are characterised by several comedians performing sequentially, one after the other in comedy shows. Nigerian comedians, therefore, create a distinct pattern of starting their individual routines, articulating their individual comic personality, catching the audience attention and then sustaining the mood in the venues of the performances.

SDTs open and start routines of comedians. Functionally, they indicate comedians' communicative intention, secure audience attention and sustain audience mood. They also establish for both comedians and audiences that mutual attention, mutual willingness and mutual beliefs are essential for the success and progress of stand-up performance. It is characteristic of the comedians to focus on themselves or their audiences in any SDT. They could foreground their personality, style or anything connected to them, and/or the presence of the audience.

\section{Extract 7. (Youngest landlord)}

Good evening ladies and gentlemen. You are welcome.

My name is youngest landlord, comedian of the Federal Republic of Nigeria.

Extract 8. (Helen Paul)

Good evening ladies and gentlemen.

Good evening mummy and daddy

Good evening friends

Open-access journal | www.europeanjournalofhumour.org 
Extracts 7 and 8 present the same orientation in performing SDT. In both instances, the comedians overtly express and acknowledge the audience as ladies and gentlemen, a lexis of reverence used in the phatic act of greeting. Ladies and gentlemen are labels that indicate that the comedians revere the presence of the audience and appreciate them. Apart from this, the labels comedian of the Federal Republic of Nigeria, mummy and daddy and friends are strategically used to perform SDT in the routines of these comedians. By introducing himself with the title comedian of the Federal Republic of Nigeria, Youngest landlord enhances his positive face as a stand-up comedian and the audience perception of his comic image. The term, a refashioning and adaptation of Nigeria's Federal Government annual merit award, foregrounds the comedian as an achiever in the stand-up comedy profession.

Helen Paul, in 8, performs SDT with a different orientation by adapting two other labels for referring to the audience- mummy and daddy and friends. By referring to her audience with mummy and daddy, she segregates them based on gender, and also, alludes to their positive face. In Nigerian English context, the terms, mummy and daddy are honorific terms which show reverence for the individuals who are thus referred to and who may not necessarily be the speaker's parents. Also, the use of friends functions as an affiliative term to show affinity as well as association with the audience as members of the same wider society. The significance of these labels is to make explicit the role of the audience in making the performance of joke possible.

Furthermore, when SDT occurs at other points in a performance, apart from the start of the performance, it signals a switch to a new joking story. I found this use of STD in the performance of Youngest landlord when he directs his greeting to Benin people in his audience, after he had performed the initial SDT at the start of his performance. This is illustrated in Extract 3 above. Although Extract 3 was discussed as an instance of code alternation in $\mathrm{C}$, given the $\mathrm{C} 2$ and the deliberate use of Benin phatic utterance, it is an instance of strategic jokeperformance-oriented salutation, as it suggests that the butts of the joke to be presented are Benin people. This instance of SDT activates in the audience the necessary stereotypes of Benin people needed for the interpretation of a joke on them. Thus, in this sense, the SDT indicates the start of another joke.

\section{Reporting Discourse Type (RDT)}

The term 'reporting' is borrowed from the concept of reported speech. Leech (2006: 101) describes reported speech as "the language we use to report what someone else said, using our own words." The concern here is the discourse function of reported speech rather than its grammatical structure. In this sense, it is seen as a meta pragmatic strategy for appropriating a communicative behaviour to an individual. It is viewed as a conventionalised and rhetorical way of characterising speakers, their speech and actions (Bublitz \& Bednarek 2006).

RDT is used by comedians to frame an action or speech as belonging to a participant in the joke. RDTs present double voiced utterances or/and actions in a covert or overt manner, in that they are layered with both the voices and actions of comedians and participants in the joke. Their significance is that they create a social distance between comedians and characters in their jokes while the comedians are narrating their joking stories. This social distance is different from the performance distance between comedians and their audiences. Performance distance is created by the institutional setting of stand-up performance which places stand-up comedians in a position of inherent authority over their audiences. The social distance is identified by the manner in which comedians assign utterances and actions to participants in their jokes, thereby distancing themselves from the actions and utterances in their joking 
stories. This social distance helps the audience to look beyond comedians and picture characters in the joke as the social actors performing the activities in the joke. Whenever RDTs are adopted, comedians display their creativity by narrating what occurred or could have occurred in a manner that serves the purpose of their interaction with the audience. In addition, as a meta-pragmatic strategy, comedians use it to present their perspectives on the actions of characters in their joke.

A typical example of RDT is found in the routine of Helen Paul, where she explicitly identifies the participant in her joke by mentioning the participant's name- Kanayo .O. Kanayo. This instance is presented below as Extract 9.

Extract 9.

I even hear say that one daddy, uncle, brother

Hum um um Kanayo.O. Kanayo

Hen he $e^{\text {vi }}$ play written by Kanayo .O. Kanayo

(AL)

Directed by by Kanayo .O. Kanayo

(AL)

Lead actor by Kanayo .O. Kanayo

(AL)

Scriptwriter by Kanayo .O. Kanayo

(AL)

Music by Kanayo .O. Kanayo

(AL)

Daddy why are you selfish?

(AL)

In Extract 9, Helen Paul adopts RDT to humorously berate Kanayo .O. Kanayo, a Nollywood actor. She overtly identifies the actor by mentioning his name and then reports to the audience the activities and actions of the actor. She adopts the strategy of exaggeration to derive the desired effect of the RDT. Helen Paul uses exaggeration in that she overstates the roles played by Kanayo .O. Kanayo in Nigerian movie making industry: she assigns to Kanayo .O. Kanayo all the key roles in the process of movie making. It should be noted that she uses Kanayo .O. Kanayo as a representative of Nollywood artists who are very versatile and could play any role assigned to them. However, her goal is not to praise the versatility of Nollywood actors but to mock the lack of specialisation of these actors who play sundry roles in other to survive in the industry.

In Youngest landlord routine, RDT is also adopted. He talks about his father, Benin people and other Nigerian stand-up comedians. His jokes on these participants and targets constitute instances of RDTs in that they are framed as performing the activities in the jokes. In Extract 4, he focuses on Benin people while in Extract 6, he talks about his father. In Extract 10 below, he focuses on other comedians.

\section{Extract 10.}

Some comedian dem go come stage dey say my papa poor, my mama poor

Is not good, you understand, because comedy now dey take another level you understand,

So it's not about coming on stage, start come dey insult your father on stage

Is very bad, say my papa poor, my papa poor, dey make audience happy

And you dey insult your father

No be lie. Many comedian wei dem papa no poor, dem dey talk am say my papa poor

My papa poor just to make the audience laugh.

[Translation: Some comedians, while on the stage, claim that their fathers and mothers are poor. This is not good because the art of comedy is taking another turn. So it is no more about coming on stage to insult your father. It is terrible to insult your father so as to make your audience happy. I am not lying; many comedians whose fathers are not poor do claim that their fathers are poor just to make their audience happy] 
Youngest landlord's RDT in Extract 10 is to lampoon other stand-up comedians for disparaging the socio-economic status of their parentage. His use of RDT is quite peculiar in that in some of the instances where he adopts it, he uses it to enhance the garden path phenomenon of his narration. The garden path is a strategy of deceiving hearers into arriving at a readily accessible interpretation of a joke, which has to be ultimately cancelled, on the strength of an incongruous punchline (Dynel 2012). Youngest landlord uses RDTs to suggest an interpretation which is easily accessible from the $\mathrm{C} 2$, which he subsequently contradicts in the $\mathrm{C} 1$ as he continues with his narration. He presents participants in his jokes and their actions from certain perspectives, which the audience interpret as below standard; however, as he goes on with his monologue, the audience will discover that what he has presented as inferior is what he has also adopted. His ultimate adoption of what he has initially rejected makes the audience realise a contradiction in the character of the stand-up comedian. In Extract 10, the comedian follows this manner of initiating humour, by presenting in his RDT that Nigerian stand-up comedians' act of casting aspersions on their parents is below par and then goes ahead to disparage his own parents.

\section{Informing Discourse Type (IDT)}

Informing discourse type occurs whenever stand-up comedians frame themselves as one of the participants in the joke. In some instances, they could frame themselves as the target of their narration. Unlike RDTs, IDTs present single voiced utterances and/or actions to the audience in that the audience are able to identify the stand-ups as the characters that are performing the actions in the joking stories. The rhetorical significance of IDTs is that audience are likely to view IDT joking story as a personal and real life experience of the stand-ups. With the IDT, stand-ups establish not just a persona of reporting an event or action but a persona narrating what $\mathrm{s} /$ he has experienced. IDTs thus place the stand-up in an advantageous position as a persona who speaks from an experienced position and also in an authorised position as a persona who has experienced the humorous side of life.

Stand-up comedians use IDTs to identify a particular feature or character which they would then eulogise or disparage. IDTs can therefore be grouped into two categories: selfpraising and self-denigrating/disparaging. In the first instance, stand-ups eulogise themselves while in the second instance, they denigrate themselves. Stand-ups' self-denigrating acts have been well covered by the literature but their self-praising acts are rarely mentioned. Usually, in self-praising acts, stand-ups narrate the manner in which they have tactically coped with situations, and/or manipulate events and situations to their advantages. Self-denigrating acts, on the other hand, identify negative traits and the impoverished state of the stand-ups.

Although self-praising and self-denigrating IDTs are identified and differentiated in Nigerian stand-up performances, their functions are somewhat similar. Both are forms of standup comedians' preconceived self-presentation and performance politics. In self-praising acts, comedians enhance their positive face as members of the society as well as their positive face as performers. With self-denigrating acts, they threaten their positive face. Threatening of their positive face is pragmatic in that they use it to present themselves as defective in some way and below socially acceptable standard, such that the audience would pity their weaknesses and exempt them from the social expectation of acceptable behaviour (Mintz 1985).

Youngest landlord demonstrates self-denigrating IDT in two instances, impoverished socio-economic-status of his parentage and his dressing. This is illustrated in Extract 5 and 6 above. On the other hand, Helen Paul exemplifies self-praising IDT. In one of the joking stories in her routine, she begins by identifying the gender biased social structure that permits only men to ask out the opposite sex. She then narrates how she, as a lady, has dealt with it. 


\section{Extract 11.}

Women, be using wisdom.

As I am, I said it now, I have branded myself.

Because I am small people don't look at me two times but now people look at me twice

This place now is packaged (touching her breast) let me show you (brings out the clothes with which she padded her burst) (intensified AL)

Total package (CL) we like to package so that boys will not be sieving us away

I even packaged this place too (brings out the cloth with which she padded her buttocks)

Total packaging (CL)

Let me tell you, stop doing ah, it is packaging!!

Although in Extract 11 Helen Paul identifies inadequacies in her physical appearance, she does not use them as the focus of the joke on herself. Rather, she emphasises what she does to overcome her incapacity, this she terms branding and packaging herself. The act of packaging and branding herself entails whatever will enhance her physical appearance as well as emphasize her sexual prowess; for instance, tucking into her dressing pieces of cloths to make her breast and buttocks seem bigger so as to attract lustful attention from men.

\section{Discussion and conclusion}

From the analysis, it can be deduced that the stand-up comedians have used the DTs to achieve their goal of making their audience laugh. The DTs identified are, therefore, communicative actions which fulfil the comedians' goal of eliciting humorous responses from the audience. Although reference has been made to the relationship of DTs to humour in the analysis, there is need to emphasize how the DTs have been used in the context of stand-up performance. The reason for this is that DTs do not naturally lead to humour in contexts where they are found.

In the routines investigated, what is peculiar is not just the choices of linguistic expressions and gestures but the fact that the comedians embedded humorous techniques in their joking stories, By doing this, the comedians make DTs found in their routines fit the purpose of stand-up comedy performance. Technically, it can be said that what makes DTs identified in stand-up performances different from DTs identified in other studies (for instance, Odebunmi 2010 and Culpeper et al. 2008) is the act of imbedding humour strategies in the DTs, such that the DTs are used for the purpose of humour. Through these humorous techniques, the audience realise that their expectations are consistently and persistently contradicted and disrupted for the period of the stand-up comedians' narration.

The techniques of exaggeration, stereotyping, verbal abuse and teasing, pun and garden path phenomenon were adopted in the routines investigated. Specifically, Helen Paul adopted pun, stereotyping and exaggeration while Youngest landlord favoured using garden path phenomenon over other humour techniques. The table below shows the assumptions, as they are adopted in garden paths in Youngest landlord's routine.

\begin{tabular}{|l|l|l|}
\hline $\begin{array}{l}\text { Discourse } \\
\text { Type }\end{array}$ & Initial Assumption & Final Assumption \\
\hline \hline RDT & $\begin{array}{l}\text { Good comedians should adopt } \\
\text { English as the language of } \\
\text { performance }\end{array}$ & $\begin{array}{l}\text { Good comedian should not speak } \\
\text { English at all, they should adopt } \\
\text { Nigerian Pidgin as language of } \\
\text { performance }\end{array}$ \\
\hline IDT & $\begin{array}{l}\text { As a good comedian, he will } \\
\text { perform using English }\end{array}$ & $\begin{array}{l}\text { As a professional comedian, he will } \\
\text { perform using Nigerian Pidgin }\end{array}$ \\
\hline
\end{tabular}




\begin{tabular}{|l|l|l|}
\hline RDT & $\begin{array}{l}\text { Nigerian comedian needs not to } \\
\text { claim that their parents are poor }\end{array}$ & $\begin{array}{l}\text { He went into comedy profession } \\
\text { because his father was very poor }\end{array}$ \\
\hline IDT & $\begin{array}{l}\text { As a comedian, he will not cast } \\
\text { aspersions on his father }\end{array}$ & $\begin{array}{l}\text { As a comedian, he has to cast } \\
\text { aspersions on his father so as to } \\
\text { make his audience laugh }\end{array}$ \\
\hline IDT & $\begin{array}{l}\text { He is well dressed for his } \\
\text { performance }\end{array}$ & $\begin{array}{l}\text { He is terribly dressed for his } \\
\text { performance }\end{array}$ \\
\hline
\end{tabular}

Furthermore, one may wonder about the validity of DTs in stand-up comedy performance. It has been argued above that DTs are identifiable by considering C2 in stand-up joke performance. Because a stand-up comedian presents several jokes in a routine, the $\mathrm{C} 2$ changes as the participants and activity in his joking stories change. In other words, as standups switch from one joke to another, they move from one $\mathrm{C} 2$ to another $\mathrm{C} 2$. The implication of this is that each change suggests a different DT which is aimed at achieving the stand-up comedians' goal of making the audience laugh and which is also aimed at maintaining and sustaining the humorous interaction with the audience.

A significance of identifying DTs is that through them, we accentuate the contextual significance of the joking stories of the stand-ups. In this sense, we look at what the stand-ups are achieving with their utterances (jokes) in the context of joke production and joke consumption. Separating C1 from C2 helps to show how stand-ups adopt and adapt context to themselves, and the contextual cues for realising their intention during performances. Each joke in a routine makes up a DT in that each joke identifies a unique activity and target(s), which are presented with the comedians' utterances. A joke, regardless of its length, sums up into a DT. The number of DTs found in performance is a function of the number of jokes presented in a performance.

\section{Appendix}

Transcription conventions

(.) Falling intonation.

(,) A pause less than 3 seconds

! Accents, it indicates emphasis. When it is more than one, it indicates a stronger degree of emphasis

? Raising intonation

(P) Significant pause, a pause more than three seconds

AC Audience claps

AL Audience laughs

CL comedian laughs

\section{Notes}

i. English is a second language in the country and it is acquired through formal education, while NP is a contact language as well as an indigenous language.

ii. Drop out is the Nigerian English term that denotes someone who had been admitted into an educational institution but could not complete the degree.

iii. oba ato kpeye is a cultural salutation in Benin dialect. 
iv. I Go Dye and Ali Baba are among the foremost stand-up comedians in Nigeria while Opa Williams is the producer and promoter of the most popular genre of Nigerian stand-up comedy.

v. Garri, which is made from cassava, is a staple food in Nigeria. It is commonly regarded as the food for the abjectly poor.

vi. An exclamation, it translates as 'aha'.

\section{References}

Adetunji, A. (2013). 'The interactional context of humour in Nigerian stand-up comedy'. Pragmatics 23 (1), pp. 1-22.

Attardo, S. (1994). Linguistic Theories of Humour. New York: Mouton de Gruyter.

Ayakoroma, B. F. (2013). 'The rise of stand-up comedy genre in Nigeria: from nothing to something in artistic entertainment'. Paper presented at the Society of Nigeria Theatre Artists Annual Conference, Benue State University, Makurdi, 4-8 June.

URL: http://www.nico.gov.ng/index.php/features/91-the-rise-of-stand-up-comedy -genrein-nigeria

Bublitz, W. \& Bednarek, M. (2006). 'Reported speech: pragmatic aspects', in Mey, J.L. (ed.), Concise Encyclopedia of Pragmatics, Oxford: Elsevier, pp. 861-864.

Culpeper, J. Crawshaw, R. \& Harrison, J. (2008). "”Activity types" and "discourse types": mediating advice in interactions between foreign language assistants and their supervisors in schools in France and England'. Multilingua 27, pp. 297-324.

Dynel, M. (2009). 'Beyond a joke: types of conversational humour'. Language and Linguistics Compass 3 (5), pp. 1284-1299.

Dynel, M. (2012). 'Garden paths, red lights and crossroads: on finding our way to understanding the cognitive mechanisms underlying jokes'. Israeli Journal of Humor Research 1 (1), pp. 6-28.

Filani, I. (2015). 'Stand-up comedy as an activity type'. Israeli Journal of Humor Research 4 (1), pp. 73-97.

Furukawa, T. (2007). "No flips in the pool”: Discursive practice in Hawai'i Creole'. Pragmatics 17 (3), pp. 371-385.

Glick, D. J. (2007). 'Some performative techniques of stand-up comedy: an exercise in the textuality of temporalization'. Language and Communication 27, pp. 291-306.

Greenbaum, A. (1999). 'Stand-up comedy as rhetorical argument: an investigation of comic culture'. Humour: International Journal of Humour Research 12 (1), pp. 33-46.

Grice, P. (1975). 'Logic and conversation', in Cole, P. \& Morgans J. L. (eds.), Syntax and Semantics 3: Speech Acts, New York: Academic Press, pp. 41-58.

Gruner, C.R. (1997). The Game of Humour: A Comprehensive Theory of Why we Laugh.

New Brunswick: Transaction Publishers.

Gumperz, J. (1982). Discourse Strategies. Cambridge: Cambridge University Press.

Gumperz, J. (1992). 'Contextualisation and understanding', in Duranti, A. \& Goodwin, A. (eds.), Rethinking Context: Language as an Interactive Phenomenon, Cambridge: Cambridge University Press, pp. 229-252.

Jodłowiec, M. (1991). 'What makes a joke tick'. UCL Working Papers in Linguistics 3, pp. 241-253.

Katayama, H. (2009). 'A cross-cultural analysis of humor in stand-up comedy in the United States and Japan'. JoLIE 2 (2), pp. 125-142.

Kim, E. (2006). 'Reasons and motivations for code-mixing and code switching'. Issues in EFL 4 (1), pp. 43-61. 
Leech, G. (2006). A Glossary of English Grammar. Edinburgh: Edinburgh University Press.

Levinson, S. C. (1979). 'Activity types and language'. Linguistics 17, pp. 365-399.

McIlvenny, P., Mettovaara, S. \& Tapio, R. (1993). 'I really wanna make you laugh: stand-up comedy and audience response', in Suojanen, M. K. \& Kulkki-Nieminen, A. (eds.), Folia, Fennistica and Linguistica: Proceedings of the Annual Finnish Linguistic Symposium May 1992, Tampere University Finnish and General Linguistic Department Publications 16, pp. 225-247.

McIntyre, D. \& Culpeper, J. (2010). 'Activity types, incongruity and humour in dramatic discourse', in McIntyre, D. \& Busse, B. (eds.), Language and Style, London: Continuum, pp. 204-222.

Mesropova, O. (2003). 'Old bags and bald sparrows: contemporary Russian female standup comedy'. Russian Review 62 (3), pp. 429-439.

Mey, J. L. (2001). Pragmatics: An Introduction. Oxford: Blackwell.

Mey, J. L. (2006). 'Pragmatic acts', in Mey, J. L. (ed.), Concise Encyclopaedia of Pragmatics, Oxford: Elsevier, pp. 747-753.

Mintz, L. E. (1985). 'Standup comedy as social and cultural mediation'. American Quarterly 37 (1), pp. 71-80.

Neria, L. (2012). Humour as Political Resistance and Social Criticism: Mexican Comics and Cinema. PhD dissertation. Fife: University of St. Andrews.

Odebunmi, A. (2010). 'Code selection at first meetings: a pragmatic analysis of doctorclient conversations in Nigeria'. InLiSt 48, pp. 1-41.

Oring, Elliott. (2003). Engaging Humor. Urbana: University of Illinois Press.

Raskin, V. (1985). Semantic Mechanisms of Humour. Dordrecht: D. Reidel.

Rutter, J. (1997). Stand-up as Interaction: Performance and Audience in Comedy Venues. $\mathrm{PhD}$ dissertation. Salford: University of Salford.

Rutter, J. (2000). 'The stand-up introduction sequence: comparing comedy comperes'. Journal of Pragmatics 32, pp. 463-483.

Sarangi, S. (2000). 'Activity types, discourse types and interactional hybridity: the case of genetic counselling', in Sarangi, S. and Coulthard, M. (eds.), Discourse and Social Life, Harlow: Longman, pp. 1-27.

Scarpetta, F. \& Spagnolli, A. (2009). 'The interactional context of humour in stand-up comedy'. Research on Language and Social Interaction 42 (3), pp. 1-22.

Schwarz, J. (2010). Linguistic Aspects of Verbal Humour in Stand-up Comedy. $\mathrm{PhD}$ dissertation. Saarland: University of Saarland.

Waisanen, D. (2011). 'Jokes inviting more than laughter ... Joan Rivers' politicalrhetorical world view'. Comedy Studies 2 (2), pp. 139-150.

Waisanen, D. (2014). 'Standing up to the politics of comedy', in Roderick, H. (ed.), Communication and Language Analysis in the Public Sphere, Hershey: IGI Global, pp. 426- 442.

Yus, F. (2003). 'Humour and the search for relevance'. Journal of Pragmatics 35, pp. 12951331.

Yus, F. (2004). 'Pragmatics of humorous strategies in El club de la comedia', in MarquezReiter, R. \& Placencia, M. E. (eds.), Current Trends in the Pragmatics of Spanish, Amsterdam/Philadelphia: John Benjamins, pp. 320-344. 